\title{
Bòvedas tabicadas: experimental and numerical analysis
}

\author{
L. Palizzolo ${ }^{1}$, S. Benfratello ${ }^{1}$, A. Caffarelli ${ }^{1}$, F. Giambanco ${ }^{2}$ \\ \& R. Urso ${ }^{3}$ \\ ${ }^{1}$ Department of Structural Engineering \& Geotechnics, \\ Palermo University, Italy \\ ${ }^{2}$ Department of History and Design in Architecture, Palermo University, \\ Italy \\ ${ }^{3}$ Innovative Concrete Experimenter Association (A.S.C.I.), Palermo, Italy
}

\begin{abstract}
A class of thin vaults, the so-called "bòvedas tabicadas", which represent one of the most common Spanish traditional building techniques at the end of XIX century are studied here, treating the relevant analysis problem through a numerical, as well as an experimental, approach. At first the problem is studied by searching for the behaviour of the material effecting suitable experiments. Once the constitutive behaviour of the materials and the structural elements are experimentally characterized, a semi inverse method for the identification of the optimum mechanical parameters to assign to an equivalent homogeneous ideal material through analysis reproducing the executed experimental tests is adopted on the grounds of finite element analysis. Moreover, other tests are processed on a real structure in order to determine the mechanical and geometric response to assigned loads. These results, compared to the related numerical analyses, can be utilized in order to propose some useful simple criteria in the reinforcing design of the referenced structures.

Keywords: bòvedas tabicadas, masonry structures, experimental and numerical analysis, maintenance, reinforcing.
\end{abstract}

\section{Introduction}

Catalan vaulting is a masonry technique perfected in Cataluña (Guastavino [1,2], Blanco [3]), which relies on fast-setting mortar for construction and on structural 
form for strength. The origins of the technique are obscure, but are likely to come from the varied cultures of the Mediterranean (Collins [4]). The technique was brought to the United States in the 1880s by Raphael Guastavino, and perfected as a monumental construction method used in many buildings.

They are better known as "bòvedas tabicadas", namely thin vaults. The Catalan name denotes a curvilinear element constituted by a succession of rasillas layers (a maximum of four layers), which are tiles characterized by the ordinary dimensions of $15 \times 30 \times 1.5 \mathrm{~cm}$, laid down flat and bulwarks along the first layer (said sencillo) with chalk pasta, and with mortar of cement and mortar in the following layers (doblado).

Although the origin and the maintenance of the technique is attributed to the Catalan culture, it seems that important examples are traceable beginning from the ancient constructive experiences of the Assiris and the Sumeris, through the Egyptians, until to the Roman period (Gulli, Mochi [5]). In particular, Collins [6], speaking about the similarity between the Catalan constructive technique and the method employed by the Romans, writes: 'A great approach to the Catalan system is observed in the Roman construction as application in the big vaults of imperial age, as for example in the Thermal baths of Caracalla constituted by sheets of tiles with the function of permanent centerings. Even if these layers of tiles don't constitute an independent structure, it is opinion of someone that the procedure remained independently after the Roman technology of the concrete declined and, consequently, it was the primordial origin of our method.'

The vaults were built in the Roman technique (figure 1) on a set of underpinnings constituted by standards and wooden transverse beams that are close and on which were put some big terracotta-tiled plates with dimensions of $60 \times 60 \mathrm{~cm}$ and tied up by chalk mortar (what will be the sencillo for the Catalans). On these was stretched a shell of chalk mortar or concrete and a second layer (doblado) of bricks, which were prepared in a discontinuous way, for brief intervals and at right angles to the walls and other bricks to assure a better connection between the masonry vault and the overhanging mass of concrete.

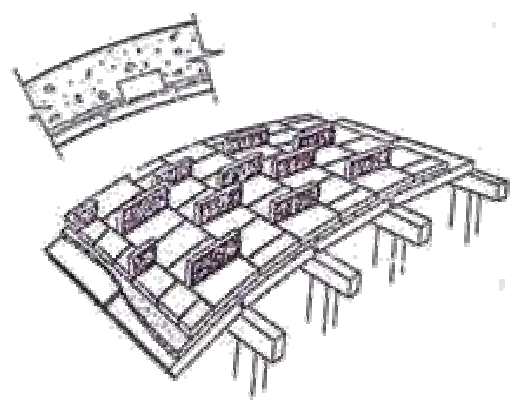

Figure 1: Typical thin vault. Roman building technique. 
The above-described method, without the employment of concrete, was used in Cataluña and also in the whole Mediterranean area in the period between the XVII and XIX centuries. Just in this period it is characterized by a condition in which in every thing the experience, the practice precede the theory, the fact precedes the law; but when the law is known, it is useful to explain the fact (Viollet Le Duc [7]). The last decades of the XIX century represent for the Cataluña and, in particular, for Barcelona, an extraordinary moment of cultural ferment and economic growth that will influence the new architecture of the Catalan Modernism. Therefore the requirement to bring on the same plan in the language of scientific explanation and that of the constructive practice induces to the formulation of new hypotheses and theories. In the same years Raphael Guastavino-Moreno started to study and to experiment (figure 2) the ability of resistance to compression, bending and shear of the tabicade construction.

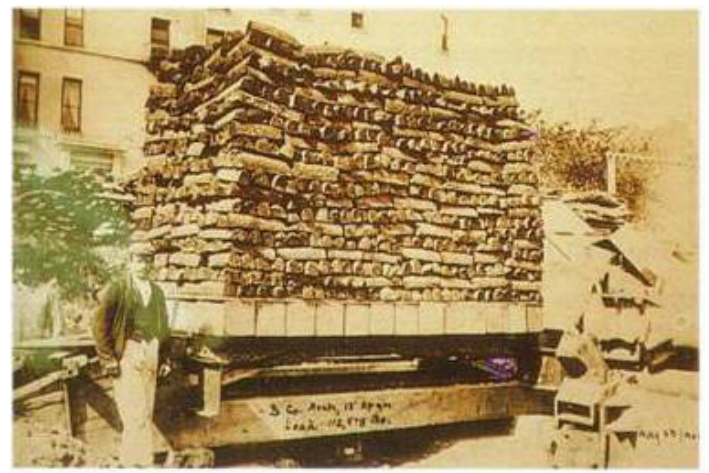

Figure 2: $\quad$ Resistance test affected by Guastavino on a thin vault.

The experimental test was affected at the Department of Tests and Experiments of the Fairbank's Staircases Company in New York; but contrary to expectations the obtained results did not give any meaningful contribution to the elaboration of a theoretical formulation for the design of the tabicade vaults.

In the same period Antony Gaudi (1852-1926) affirms that 'the boveda tabicada is the most precious element of our construction: it allows to perform with simplicity and rapidity the most complex forms, the presence of centerings are not necessary and it offers big resistance in relation to his lightness and the simplicity of its components. (...) for verifying a boveda tabicada it is necessary at first to trace, overlapped to the axis of the vault and starting from the imposts, the funicular whose length is equal to the axis corresponding to the dead weight and the overloads; then suitable virtual forces are necessary to put the funicular inside the thickness of the vault, in the way that it coincides with the axis of the vault; finally, it is possible to determine the strengths of traction which are in equilibrium with the above mentioned auxiliary forces. If these tractions are sustainable by the mortar or by the binder of the rasillas, the vault verifies; on the contrary it is necessary to adopt a conglomerate of greater resistance, to 
increase the thickness of the vault or to reinforce the mortar with the layers of rasillas in the part subjected to excessive tractions' (Bergós Massó [8]).

In the first fifty years of last century, during the period in which the most important constructive technique was related to frame structure realized by reinforced concrete or steel, the architect Eladio Dieste used it in all of his potential productions, which characterized the iron and the reinforced concrete with the contribution of the traditional materials and techniques. According to Viollet Le Duc, which states that the experience and the practice come before the theory, he studied the behaviour of reinforced thin vaults on a small scale and then on a large scale. Dieste combines the tradition and the innovation, testing the technique of the bòveda tabicada whose extrados is reinforced by a thin coat of concrete.

During this last century the technique of the bòveda tabicada has been slowly declining. On the contrary, the scientific interest today is revaluated and renewed, in particular in the restoration and in the maintenance of ancient buildings, namely in all the cases where a structural renewal characterized by the preference for the traditional techniques and materials always with respect to the safety requisites prescribed by the current rules is necessary.

In the present paper the study related to an existing vaulted structure is reported. In particular, starting from the results obtained in a previous paper performed by the same authors and related to a resistance model of the material, a numerical computation of the vault has been effected and the results are compared with the ones deduced by the experimental test.

\section{Experimental results and material modelling}

The first stage of study, which was necessary in order to interpret the whole structural behaviour, is related with the definition of a suitable model able to represent the material behaviour. With this aim it has been possible to effect experimental compression and bending tests, utilizing some samples taken from a building of the historic centre of Palermo, where some structural elements, mainly constituting walls, are made with the same technique of the "bòvedas tabicadas".

The typical element is constituted by three layers of bricks with dimensions $26 \times 13 \times 2 \mathrm{~cm}$ connected by mortar of lime and plaster. On these samples the experimental tests described in the following section have been affected at the Laboratory of the Department of Structural Engineering and Geotechnics of the University of Palermo. In particular, one sample has been put to the compression test, while another two samples have been put to bending tests.

\subsection{Experimental results}

The compression test (further details in Benfratello et al [9]) has been carried out on a sample with dimensions $32.25 \times 32.15 \times 11.50 \mathrm{~cm}$ (figure 3 ).

The obtained results, in terms of stress and strain, are plotted in figure 4 . As it is possible to observe the sample exhibits at first a linear elastic behaviour until a 
stress of 2.6 MPa value with a tangent elastic modulus valuable in $1.6 \mathrm{GPa}$. Above such a stress limit, when the fractures began to manifest themselves, the sample exhibits the ability to resist to a stress nearly constant with restricted pseudoplastic deformations.

This behaviour is followed by the onset of new and greater fractures related with a decreasing of the resistance of the sample until its definitive collapse.

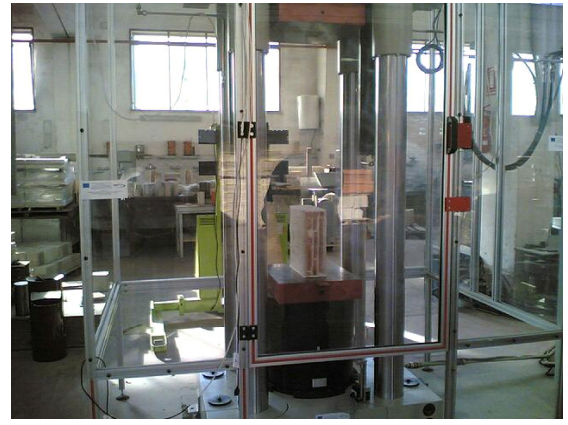

a)

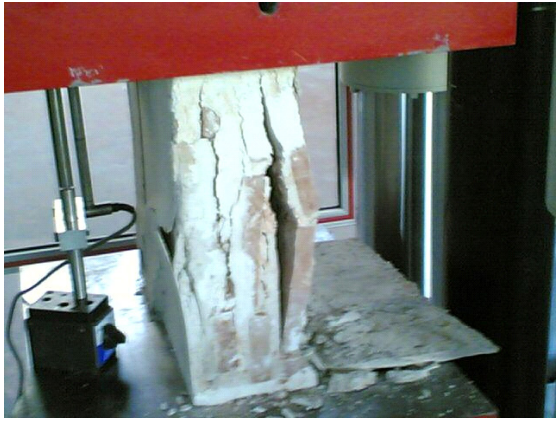

b)

Figure 3: Compression test: a) test engine; b) sample fracture.

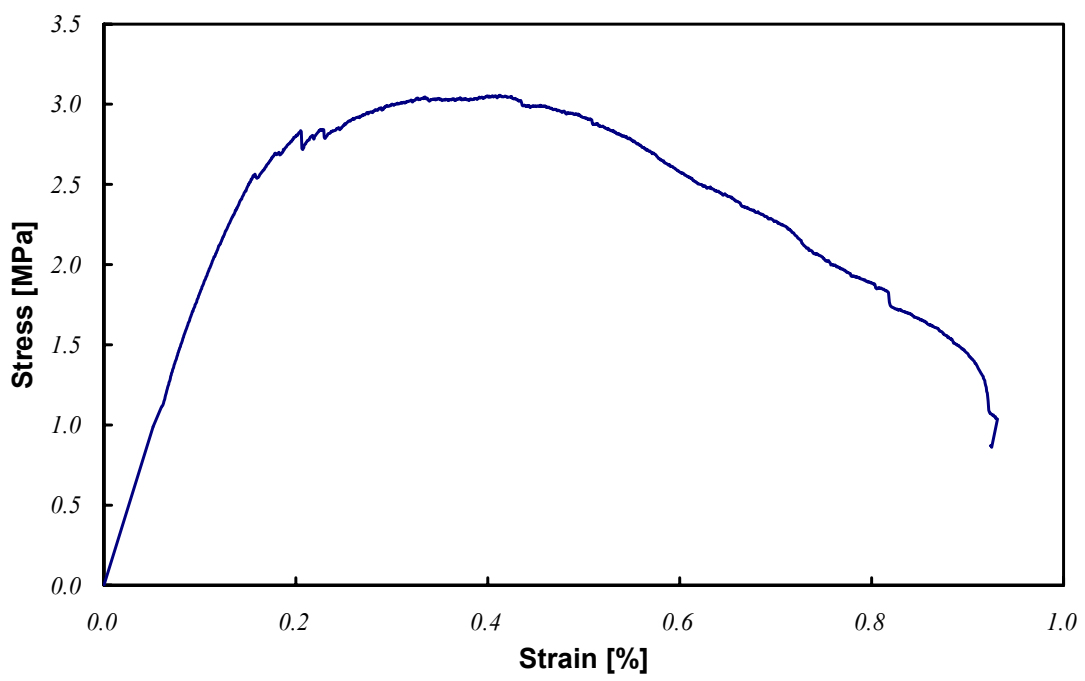

Figure 4: $\quad$ Stress-strain diagram deduced by the compression test.

Another two samples, collected by the same wall, have been subjected to bending tests. The sample dimensions are $36.5 \times 101 \times 11 \mathrm{~cm}$ and $37 \times 101 \times 11 \mathrm{~cm}$ for the three-point and four-point bending tests, respectively. In figures 5 and 6 the test engine, scheme and results (in terms of load-displacement) for the same tests are reported, respectively. 
As it is possible to observe, both the obtained diagrams show a nearly linear behaviour till the collapse, related with the limited resistance of the material to tensile stress.

\subsection{Material modelling}

In order to interpret and define the material behaviour, the tests described at the previous section have been reproduced analytically by utilizing the program ADINA 8.3 assuming a homogeneous material. Furthermore, the "concrete" model has been adopted, present in ADINA program library, identifying such a model by means of the results obtained by the compression test.

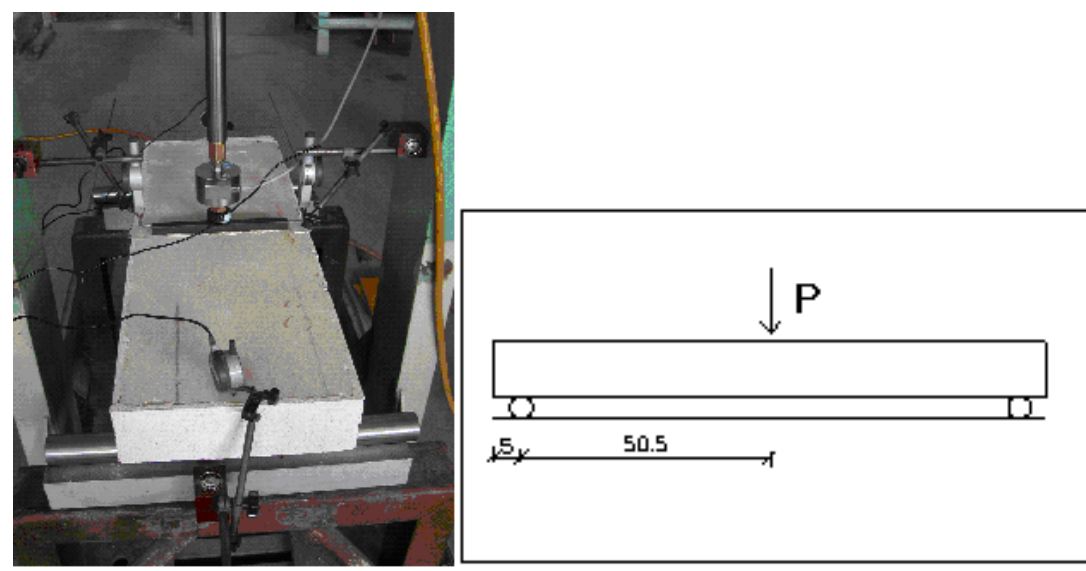

a)

b)

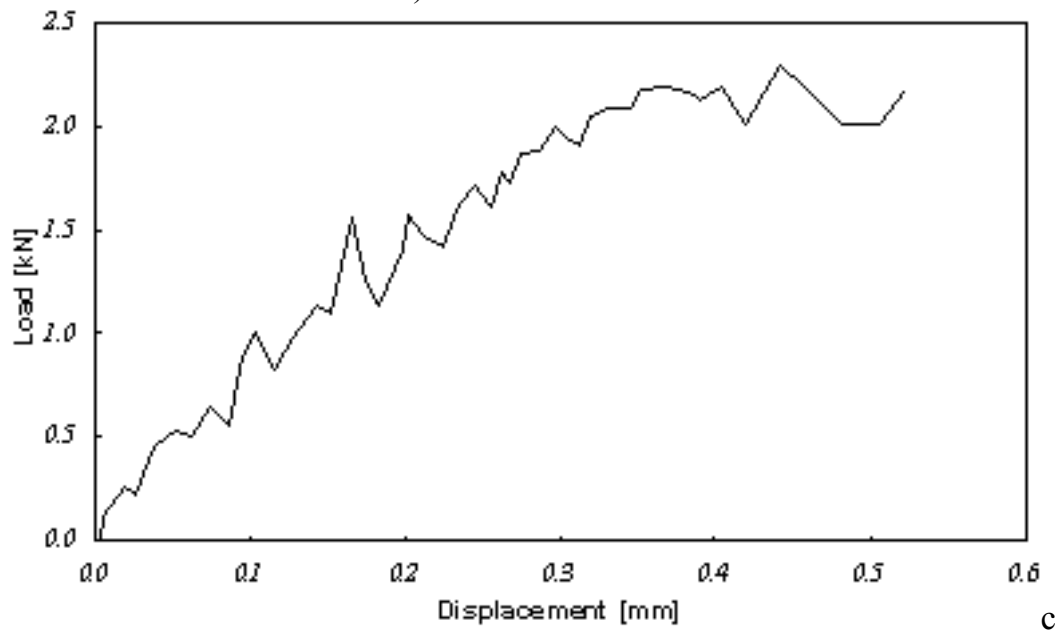

Figure 5: Three-point bending test: a) test engine; b) test scheme; c) test results. 

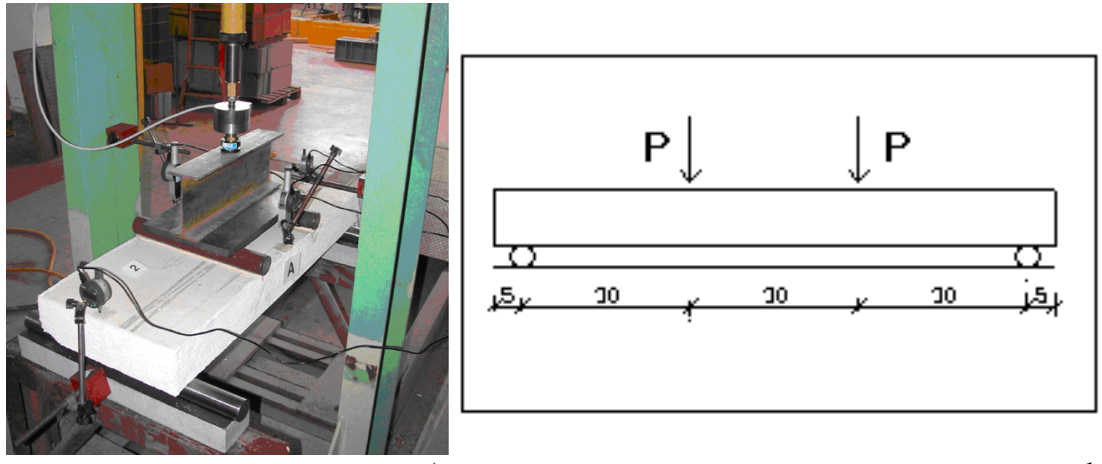

a)

b)

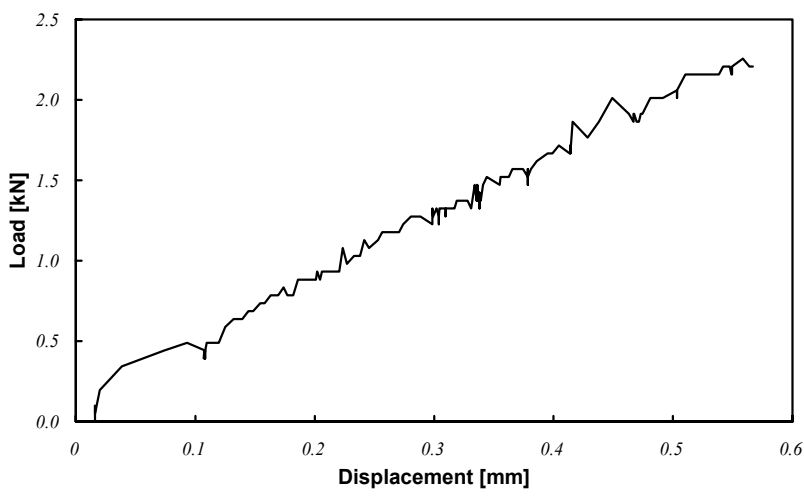

c)

Figure 6: Four-point bending test: a) test engine; b) test scheme; c) test results.

The utilized mesh has been characterized by 40396 four-node elements; a parametric computation has been effected on varying the tensile resistance of the material. The results, obtained for a tensile stress resistance equal to $80 \mathrm{kPa}$, are reported in figure 7 for the three and four point-bending test, respectively.

\section{Experimental results and vault numerical analysis}

Once the material behaviour has been identified and correctly modelled in a numerical way, the structural behaviour of a real vault has been investigated experimentally as well as numerically. By experimental tests the vertical displacements of three points (figure 8a) due to a distributed load (ranging from 0.0 to $4.0 \mathrm{kN} / \mathrm{m}^{2}$ ) have been measured. The measurement setup was constituted of three HBM WTS20 gauges connected to a HBM UPM60 device. The vault examined in this section (figure 8a,b) lies in an ancient palace different from that from which the samples described in the foregoing section have been taken. This remark implies that the two materials can be slightly different each other. 
510 High Performance Structures and Materials IV

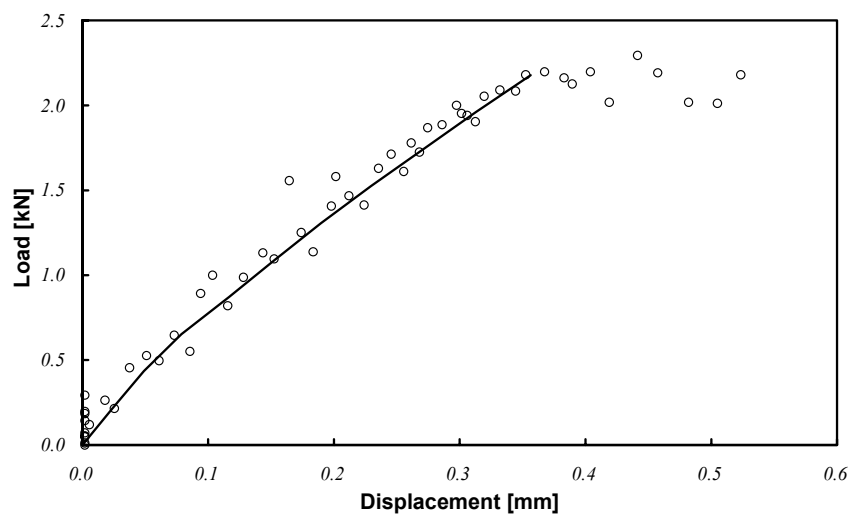

a)

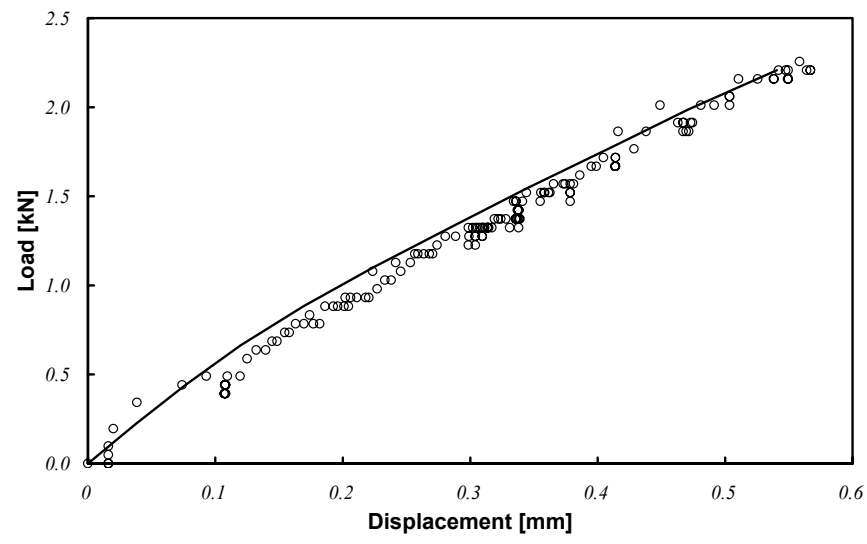

b)

Figure 7: Comparison between experimental and numerical results: a) three-point bending test; b) four-point bending test. (o) experimental results; (continuous line) numerical results.

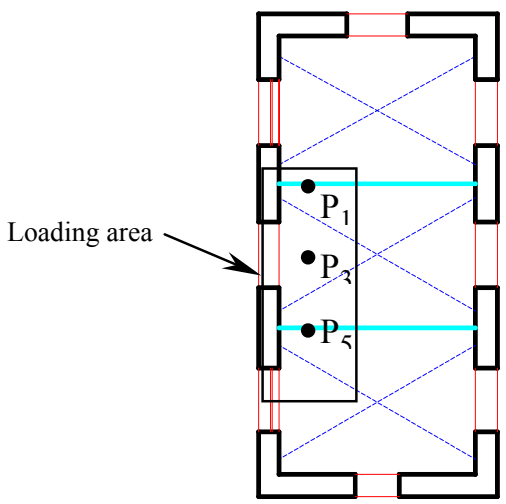

a)

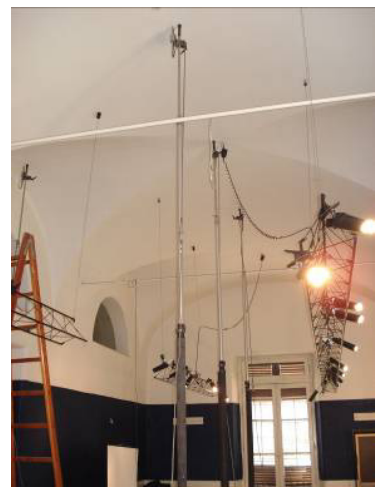

b)

Figure 8: a) Sketch of the vault plan; b) Photo of the vault. 
Moreover, the vault is constituted of four layers while the samples examined in the foregoing section were constituted of three layers. This fact will be taken in the numerical analysis by increasing the initial tangent modulus. The numerical model (figure 9) is constituted of 21368 3D four-nodes elements and two different materials: concrete model for the masonry with mechanical parameters obtained in the foregoing section, and elastic model for the tie rods with mechanical parameters of a steel. The boundary conditions are all of fixed joint. In figure 10 the experimental and numerical results are compared.

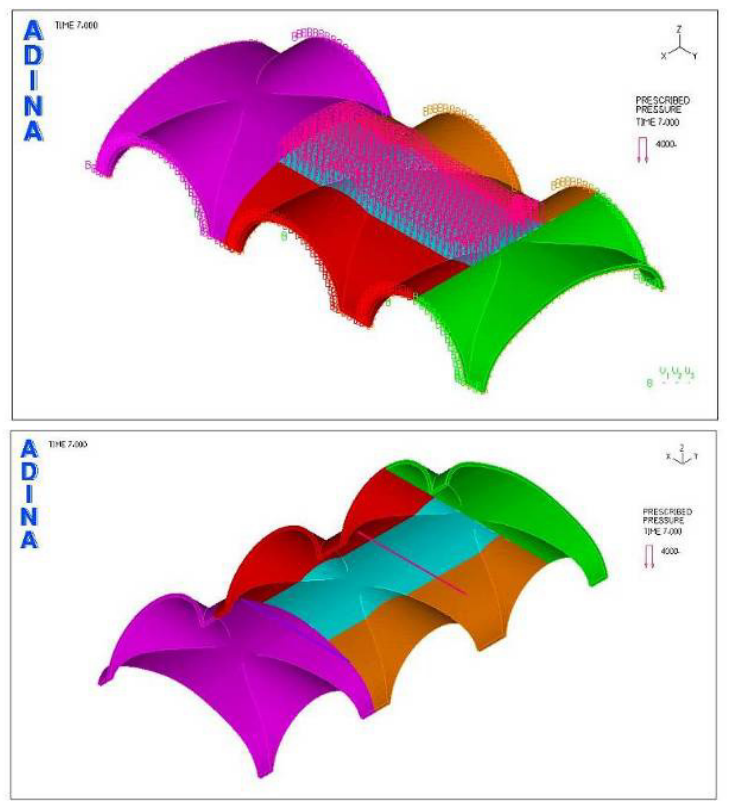

a)

b)

Figure 9: ADINA model of the vault: a) bird's eye view; b) view from below.

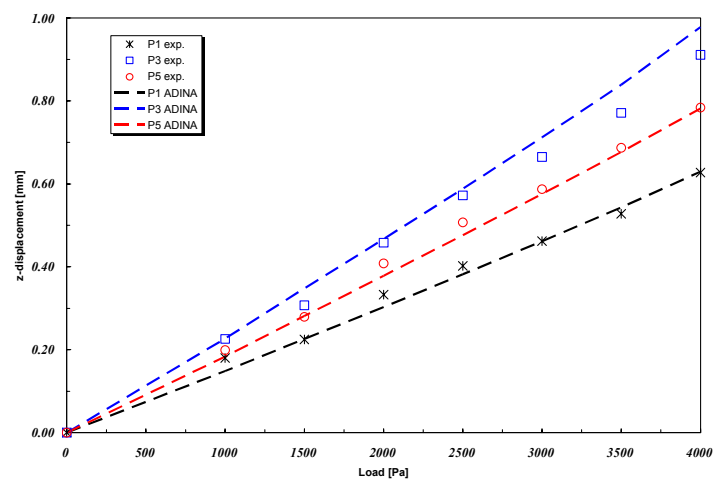

Figure 10: Comparison between experimental and numerical results. 


\section{Conclusions}

The present paper has been devoted to the study of thin vaults, the so called "bòvedas tabicadas". At first the material behaviour has been described and discussed on the grounds of previous study related to experimental and suitable numerical analysis. Moreover a thin vault has been identified and an appropriate experimental test has been used for computing the vertical displacements of three suitably chosen points under a distributed quasi static increasing load. The relevant structure has then been discretized into $3 \mathrm{D}$ finite elements in order to obtain a useful computational model. By utilizing ADINA program and by utilizing a material model appropriately modified in order to take into account the different topology of the actual structure, interesting numerical results have been obtained. Other developments will be performed both from a numerical and experimental point of view with the aim of acquiring deeper information on material behaviour as well as on vault structure response. Further investigations will be effected in order to determine the best approach to the reinforcing and the maintenance of the relevant vaulted structures.

\section{References}

[1] Guastavino Moreno, R., Cohesive construction: its past, its present and its future. The American Architect and Building News, 41, 922, pp 125-129, 1893.

[2] Guastavino Moreno, R., Essay on the theory and history of cohesive construction, applied especially to the timber vault, 2a Ed. Boston: Ticknor and Co., 1893.

[3] Moya Blanco, L., Bovedas tabicadas- Madrid: Colegio oficial de arquitectos de Madrid, 1993. Ripr.facs. dell'ed: Ministerio de la gobernacion, 1947.

[4] Collins, G.R., The Transfer of Thin Masonry Vaulting from Spain to America. American Society of Architectural Historians Journal, 27, 3, pp. 176-201, 1968.

[5] Gulli, R., Mochi, G., Il recupero delle volte in foglio attraverso la costruzione tabicada. Costruire in laterizio. Architetture voltate, 82; pp. 6673, 2001.

[6] Collins, G.R., Antonio Gaudì, in I maestri dell'architettura contemporanea, il Saggiatore, Milano, 1960.

[7] Viollet Le Duc, E., L'architettura ragionata, Ed. Jaca Book, 2002.

[8] Bergós Massó, J., Materiales y elementos de costrucion, in Fantone C.R., Il mondo organico di Gaudì architetto costruttore, Edizione Alinea, 1999.

[9] Benfratello, S., Caffarelli, A., Palizzolo, L., Giambanco, F., Urso, R., Analisi numerica e sperimentale sul comportamento meccanico delle volte catalane, Sperimentazione06 - Sperimentazione su materiali e strutture, ed. Salvatore Russo ed Enzo Siviero, pp. 269-278, 2006. 